\title{
Tipos de aberturas dos grãos de pólen de espécies de Passiflora L. (Passifloraceae) ${ }^{1}$
}

\author{
Greta Aline Dettke ${ }^{2,4}$ e Rinaldo Pires dos Santos ${ }^{3}$
}

Recebido em 09/04/2009. Aceito em 15/09/2009

RESUMO - (Tipos de aberturas dos grãos de pólen de espécies de Passiflora L. (Passifloraceae)). Estudos palinológicos revelam uma ampla variação de formas, número e tipos de aberturas nos grãos de pólen em Passiflora. Este estudo tem como objetivo caracterizar as aberturas polínicas de onze espécies do gênero ocorrentes no Rio Grande do Sul e duas em Santa Catarina (Brasil), pertencentes a três dos quatro subgêneros atualmente reconhecidos: Astrophea, Decaloba e Passiflora. Foram utilizadas várias técnicas de microscopia óptica de campo claro e microscopia eletrônica de varredura. Passiflora haematostigma (Astrophea) possui grãos de pólen 6-colporados, com três endoaberturas lalongadas. Passiflora alata, P. amethystina, P. caerulea e P. edulis (Passiflora) apresentam pólen 6-colpados, com fusões das ectoaberturas, aos pares, na região do apocolpo. Passiflora actinia, P. elegans e P. tenuifila (Passiflora) apresentam grãos de pólen com 6 a 12 colpos, também fusionados aos pares. Passiflora misera, P. morifolia, P. suberosa e P. truncata (Decaloba) apresentam grãos de pólen 6-colporados operculados, com diferenças no tamanho das endoaberturas e largura do opérculo. Passiflora capsularis (Decaloba) apresenta pólen 12-colporado. São discutidos os principais termos relacionados às descrições polínicas do grupo e indicados os termos mais apropriados e sinônimos.

Palavras-chave: Passiflora, tipos aperturais, pseudopérculo, opérculo, palinologia

ABSTRACT - (Aperture types of pollen grains of Passiflora L. species (Passifloraceae)). Palynological studies reveal a wide variation in shape, number and types of apertures in Passiflora pollen grains. This study aimed to characterize pollen grain apertures of eleven species of Passiflora from Rio Grande do Sul state and two species from Santa Catarina state (Brazil), belonging to three of the four subgenera now recognized: Astrophea, Decaloba and Passiflora. Several techniques of light and scanning electron microscopy were employed. Passiflora haematostigma (Astrophea) has 6-colporate pollen grains with three lalongate endoapertures. Passiflora alata, P. amethystina, P. caerulea and P. edulis (Passiflora) have 6-colpate pollen grains, with fusion of ectoapertures pairs in the apocolpium. Passiflora actinia, P. elegans and P. tenuifila (Passiflora) have pollen grains with 6 to 12 colpi, also fused in pairs. Passiflora misera, P. morifolia, P. suberosa and P. truncata (Decaloba) have 6-colporate operculate pollen grains, with differences in endoaperture size and operculum width. Passiflora capsularis (Decaloba) has 12-colporate pollen. The main palynological terms and synonyms in the literature are discussed. Key words: Passiflora, aperture types, pseudoperculum, operculum, palynology

\section{Introdução}

Passiflora L. é o maior dos gêneros de Passifloraceae, com cerca de 530 espécies (Feuillet \& MacDougal 2007). No Brasil, Cervi (2006) refere um total de, aproximadamente, 140 espécies validamente descritas para o gênero. Este gênero apresenta uma classificação bastante complexa, com a distinção de 23 subgêneros (Killip 1938; Escobar 1989). Recentemente, a delimitação dos níveis infragenéricos é questionada num contexto de análises filogenéticas baseadas também em seqüências gênicas. Feuillet \& MacDougal (2003) propõem, com base na morfologia externa e características ecológicas das espécies, uma nova classificação infragenérica para Passiflora, reduzindo o número de subgêneros para apenas quatro: Astrophea (DC.) Mast., Deidamioides (Harms) Killip, Decaloba (DC.) Rchb. e Passiflora L. Esta proposta tem sido parcialmente confirmada por estudos de filogenia molecular (Muschner et al. 2003; Yockteng \& Nadot 2004; Muschner 2005; Souza-Chies et al. 2005; Hansen et al. 2006).

Do ponto de vista palinológico, Passifloraceae mostrase uma família bastante interessante, pois os grãos de pólen apresentam grande variabilidade de características, algumas ainda fracamente exploradas do ponto de vista sistemático e filogenético. As primeiras observações sobre a morfologia dos grãos de pólen foram relatadas por Mohl (1834), Fritzsche (1837) e Fischer (1890). Posteriormente, Erdtman (1952) descreve, em seu tratado, os grãos de pólen de sete espécies de Passifloraceae, pertencentes aos gêneros Mitostemma Mast., Passiflora e Tetrapathaea (DC.) Rchb., como possuindo de três a 12 colpos ou cólporos e exina reticulada. Em 1965, dois importantes trabalhos são publicados, simultaneamente, por Spirlet (1965) e Presting (1965). O primeiro trata da utilização taxonômica dos grãos de pólen de Passifloraceae, revelando uma ampla gama de características relevantes para o grupo, desde a estrutura da exina até a complexa gradação de vários tipos de aberturas. Presting (1965) realiza o estudo até então mais abrangente e pormenorizado sobre os grãos de pólen de Passifloraceae, contemplando 153 espécies da família, distribuídas em 13 gêneros, destacando a importância do entendimento da evolução das aberturas dos grãos de pólen de Passifloraceae para a realização das descrições polínicas.

Parte da Dissertação de Mestrado da primeira autora

2 Programa de Pós-Graduação em Botânica, Universidade Federal do Rio Grande do Sul, Av. Bento Gonçalves 9500, Bloco IV, Prédio 43433, Campus do Vale, Porto Alegre, RS, Brasil

3 Professor Adjunto. Laboratório de Anatomia Vegetal, Departamento de Botânica, Instituto de Biociências, Universidade Federal do Rio Grande do Sul, Porto Alegre, RS, Brasil

4 Autor para correspondência: gretadet@yahoo.com.br 
Após as publicações de Presting (1965) e Spirlet (1965), poucos estudos foram realizados com grãos de pólen de Passifloraceae. Destacam-se, entre eles, o de Amela García et al. (2002), no estudo da microesporogênese, microgametogênese e morfologia polínica de seis espécies de Passiflora da Argentina; Araújo \& Santos (2004), com o estudo morfológico de 12 espécies de Passiflora da Bahia, estabelecendo três tipos polínicos entre as espécies estudadas; Milwardde-Azevedo et al. (2004), com a descrição polínica de oito espécies de Passiflora, subgênero Decaloba; e Barrios et al. (2005), com a caracterização de 121 espécies de Passiflora e duas espécies de Dilkea Mast. e aplicação da morfologia polínica à nova classificação infragenérica de Passiflora.

Em estudos anteriores, que abrangem os grãos de pólen de Passifloraceae e do gênero Passiflora, percebe-se a utilização de diferentes termos para as diferentes regiões da esporoderme. Esses termos se complementam e giram em torno de um conceito de evolução similar para as aberturas do pólen, como pontopérculo, opérculo primário, opérculo secundário e pseudopérculo (Erdtman 1952; Spirlet 1965; Presting 1965). Contudo, na literatura recente, verifica-se que esses termos não têm sido aplicados sempre de forma correta e algumas vezes são confundidos pelos autores, comprometendo as descrições polínicas e, consequentemente, a aplicação dos seus resultados. Assim, não há consenso quanto ao tipo e número de aberturas em muitas espécies. Por exemplo, o pólen de $P$. suberosa pode ser descrito como 6-colpado, com opérculos sobre os colpos (Araújo \& Santos 2004), 6-colporado, com opérculos secundários (Presting 1965) ou 12-colpado (Milward-de-Azevedo et al. 2004). Nesses casos, é necessária a análise mais minuciosa dos tipos aperturais, se possível com vários métodos de abordagem, podendo então ser indicados, com mais segurança, o número e forma das aberturas, bem como a presença ou não de opérculos.

Desse modo, o presente estudo tem por objetivo a análise dos tipos aperturais de onze espécies de Passiflora que ocorrem no estado do Rio Grande do Sul e duas espécies de Santa Catarina, pertencentes a três subgêneros (Feuillet \& MacDougal 2003), Astrophea, Decaloba e Passiflora, utilizando diferentes técnicas de microscopia óptica de campo claro e microscopia eletrônica de varredura. Também se pretende discutir as diferentes nomenclaturas propostas para os grãos de pólen da família, os termos sinônimos, bem como indicar os termos mais adequados para as diversas estruturas, a fim de uniformizar as descrições polínicas.

\section{Materiais e métodos}

Foram estudadas as seguintes espécies, cujo material testemunho das populações estudadas está depositado no Herbário do Instituto de Biociências da Universidade Federal do Rio Grande do Sul (ICN). Segue a relação do material estudado: subgênero Astrophea (DC.) Mast.: Passiflora haematostigma Mart. ex Mast. - BRASIL. Santa Catarina: Santa Rosa de Lima, 07-IX-2007, fl., G.A. Dettke \& A. Silvério 70 (ICN); São Martinho, 31-X-2007, fl., L.F. Lima \& G.A. Dettke 512 (ICN); subgênero Decaloba (DC.) Rchb.: P. capsularis L. - BRASIL. Rio Grande do Sul: Porto Alegre,
30-X-2007, fl., G.A. Dettke 65 (ICN); Sapiranga, 11-II-2008, fl. fr., G.A. Dettke 97 (ICN); Maquiné, 14-II-2008, fl. fr., G.A. Dettke 102 (ICN); P. misera Kunth - BRASIL. Rio Grande do Sul: Porto Alegre, 30-X-2007, fl., G.A. Dettke 64 (ICN); Guaíba, 27-IX-2007, fl. fr., G.A. Dettke 81 (ICN); P. morifolia Mast. - BRASIL. Rio Grande do Sul: Augusto Pestana, 18IV-2008, fl., S.M. Kerpel s.n. (ICN159142); P. suberosa L. - BRASIL. Rio Grande do Sul: Guaíba, 28-IX-2007, fl., G.A. Dettke 60 (ICN); Guaíba, 27XI-2007, fl. fr., G.A. Dettke 84 (ICN); Porto Alegre, 22-I-2008, fl. fr., G.A. Dettke 95 (ICN); Porto Alegre, 11-IX-2007, fl. fr., G.A. Dettke 75 (ICN); Osório, 06-IX-2007, fl., G.A. Dettke 73 (ICN); P. truncata Regel - BRASIL. Santa Catarina: Santa Rosa de Lima, 01-XI-2007, fl. fr., L.F. Lima \& G.A. Dettke 520 (ICN); e subgênero Passiflora L.: P. actinia Hook. - BRASIL. Rio Grande do Sul: Porto Alegre, 22-X-2007, fl., G.A. Dettke 63 (ICN); P. alata Curtis - BRASIL. Rio Grande do Sul: Porto Alegre, 23-XI-2007, fl., G.A. Dettke 85 (ICN); Guaíba, 15-VI-2007, fl., G.G. Souza 01 (ICN); P. amethystina J.C. Mikan - BRASIL. Rio Grande do Sul: Osório, 06-XI2007, fl., G.A. Dettke 74 (ICN); P. caerulea L. - BRASIL. Santa Catarina: Lages, 01-XI-2007, fl. fr., G.A. Dettke 67 (ICN); Rio Grande do Sul: Guaíba, 28-IX-2007, fl., G.A. Dettke 62 (ICN); Osório, 06-XI-2007, fl., G.A. Dettke 72 (ICN); P. edulis fo. flavicarpa O. Deg. - BRASIL. Rio Grande do Sul: Osório, 06-XI-2007, fl., G.A. Dettke 76 (ICN); Torres, 14-XI-2008, fl., G.A. Dettke 215 (ICN); P. elegans Mast. - BRASIL. Rio Grande do Sul: Guaíba, 28-IX-2007, fl., G.A. Dettke 59 (ICN); P. tenuifila Killip - BRASIL. Rio Grande do Sul: Porto Alegre, 29-XI-2007, fl. fr., G.A. Dettke 87 (ICN).

Para a análise em microscopia óptica de campo claro, foram utilizadas duas técnicas: a) acetólise dos grãos de pólen (Erdtman 1960), sendo que parte destes foi montada em lâminas palinológicas com gelatina glicerinada, e parte incluída em resina acrílica a base de hidroxietilmetacrilato (Tecnovith 7100, Kulzer) (Gerrits \& Smid 1983); b) inclusão de grãos de pólen, quimicamente fixados, em resina acrílica, para a confecção de seções semifinas, em diversos planos, dos grãos de pólen. Para esta segunda técnica, os grãos de pólen, ainda no interior das anteras, foram fixados em uma mistura de glutaraldeído $2,5 \%$ e formaldeído $2 \%$ em tampão fosfato de sódio 0,1 M,pH 7,2 (Roland \& Vian 1991) e, após lavagem em tampão de mesma osmolaridade, o material foi desidratado em série crescente de etanol e incluído em resina acrílica. Seções semifinas, de 0,5 a $2 \mu \mathrm{m}$, foram obtidas em micrótomo de rotação, equipado com navalhas descartáveis de vidro e montadas sobre lâminas histológicas. Para a análise das regiões das aberturas e da exina dos opérculos e mesocolpos, foram utilizados como corantes/testes histoquímicos: Azul de Toluidina O (C.I. 52040), em concentração de $0,05 \%$ e pH 4,4 (O’Brien \& McCully 1981); Azul de Alcião $8 \mathrm{GX} 1 \%$ (C.I. 74240), em solução acética 3\%, para ácidos polissacarídicos e ácidos pécticos (para a intina) (Jensen 1962); Fucsina Básica (C.I. 42500) $0,05 \%$ em solução alcoólica 2,5\% (para a ectexina e endexina) (Faegri \& Iversen 1964; Punt et al. 2007).

Para a análise em microscopia eletrônica de varredura (MEV), parte das anteras fixadas foi desidratada em série crescente de etanol, transferida para acetona $100 \%$ e processadas em secador de ponto crítico. As anteras foram montadas em fita adesiva metálica sobre suportes de alumínio e fraturadas (com uso de pinça de ponta fina) para a observação dos grãos de pólen. Parte do pólen acetolisado, após lavagem, foi ressuspendido em água destilada. Uma gota da solução foi transferida para a superfície de 1 $\mathrm{cm}^{2}$ de filme fotográfico (previamente exposto à luz e revelado), sobre o lado da emulsão, e aderido em suportes de alumínio. O filme fotográfico foi seco em estufa aquecida a $60^{\circ} \mathrm{C}$. Os grãos de pólen, secos e aderidos sobre o filme fotográfico, foram recobertos com fita adesiva, sendo esta rapidamente removida, em um único movimento, obtendo-se grãos de pólen fraturados (Claugher 1986). O material foi recoberto com 10 a 15 nm de ouro e observado em microscópio eletrônico de varredura Jeol JSM 6060 , sob $10 \mathrm{kV}$.

\section{Resultados e discussão}

Este estudo comprova, entre as espécies estudadas, a variação no número e tipo de aberturas, como ressaltado em diversos estudos palinológicos de Passifloraceae (Tab. 1).

Entre as espécies estudadas, verifica-se a existência de três grandes grupos ou "tendências", baseados na morfologia 
polínica, cujas espécies representam os três subgêneros, Astrophea, Passiflora e Decaloba, conforme classificação de Feuilett \& MacDougal (2003).

A espécie representante do subgênero Astrophea, $P$. haematostigma, possui grãos de pólen 6-colporados, com 3 endoaberturas lalongadas (Figs. 1-6, Tab. 1). As ectoaberturas encontram-se arranjadas aos pares, mas não apresentam fusões na região do apocolpo. Esta espécie apresenta pontopérculo, de acordo com a definição de Erdtman (1952), também utilizada por Punt et al. (2007). Nesta espécie, os pontopérculos, juntamente com a região do apocolpo, formam uma estrutura trirradiada, como assinalado por Araújo \& Santos (2004) para outra espécie do subgênero Astrophea ( $P$. rhamnifolia Mast.). Cada endoabertura está associada a duas ectoaberturas pareadas (Figs. 4-6), conforme também descrito para P. rhamnifolia (Araújo \& Santos 2004).

De acordo com a teoria de Presting (1965), os grãos de pólen com seis aberturas e derivados, característicos de espécies de Passiflora, possuem origem a partir de grãos 3-colporados, que desenvolveram opérculos sobre as aberturas. Estes opérculos tornaram-se mais largos e suas duas extremidades fundiram-se na região do apocolpo, deixando de ser funcionalmente opérculos e incorporando-se ao mesocolpo. Cada um passou a delimitar, nestes novos grãos, duas novas aberturas. Presting (1965) chama estes opérculos de opérculos primários (die Primäropercula), sendo denominados, neste trabalho, pontopérculos. Ainda segundo Presting (1965), as endoaberturas, sob estes opérculos, podem permanecer únicas e alongar-se (lalongadas) ou podem individualizar-se pela deposição adicional de endexina na superfície interna do opérculo primário, originando então seis endoaberturas.

O que Presting (1965) denomina de opérculo primário corresponde ao que Erdtman (1952) chama de pontopérculo, cujo conceito foi utilizado posteriormente por Spirlet (1965) e Araújo \& Santos (2004). Assim, estes termos podem ser considerados sinônimos, dando-se preferência para a utilização do termo pontopérculo, que se encontra mais difundido na literatura (Punt et al. 2007) e gera menos confusão que o emprego do termo opérculo primário, já que também existem, na literatura, os termos opérculo secundário e opérculo. Outro termo utilizado para a descrição destes grãos de pólen é geminicolpado (Amela García et al. 2002) (ou geminicolporado, no caso), referindo-se à disposição pareada das aberturas (Fig. 4) e sinonimizado por Punt et al. (2007) como pontopérculo.

As espécies estudadas do subgênero Passiflora (Figs. 7-15, Tab. 1) apresentam tipo de abertura distinto de $P$. haematostigma. Nestas espécies, observa-se a fusão de colpos na região do apocolpo. P. alata (Fig. 8), P. caerulea (Fig. 10), P. amethystina (Fig. 11) e P. edulis apresentam grãos de pólen 6-sincolpados (seis colpos fundidos aos pares na região do apocolpo). P. actinia apresenta de 10 a 12 colpos; P. elegans e P. tenuifila (Fig. 14) apresentam de 8 a 10 colpos, pantoaperturados, com aberturas fundidas aos pares
(Figs. 13 e 14). Nestas espécies, não foram encontradas endoaberturas, seja em microscopia óptica de campo claro como em microscopia eletrônica de varredura (MEV) de grão acetolisados e fraturados (Fig. 12).

De acordo com Presting (1965), estes grãos de pólen têm origem a partir de grãos de pólen 6-colporados (como os de $P$. haematostigma), nos quais as ectoaberturas se fusionam aos pares no apocolpo. Em relação às endoaberturas, observase uma clara tendência, segundo o autor, de tornarem-se reduzidas ou desaparecerem por completo. Após a fusão, partes do mesocolpo são delimitadas por estas aberturas e estas regiões são denominadas de pseudopérculos (die Pseudopercula), pois funcionam como opérculos durante a germinação dos grãos de pólen sobre o estigma e, frequentemente, se desprendem nas preparações palinológicas (Fig. 11). Contudo, na realidade, são originalmente mesocolpos. Para Presting (1965), de forma inexplicável, o número de pseudopérculos pode chegar a 12 (representando 24 aberturas fundidas aos pares), distribuídos uniformemente por toda a esporoderme. Spirlet (1965) explica a formação deste tipo polínico por meio de fusões longitudinais e também transversais dos colpos.

Com relação ao número de aberturas, este estudo concorda com a maioria dos estudos envolvendo espécies do subgênero Passiflora (Erdtman 1952; Presting 1965; Spirlet 1965; Huynh 1972; Amela García et al. 2002; Araújo \& Santos 2004; Milward-de-Azevedo et al. 2004; Barrios et al. 2005), diferindo apenas para P. alata, na qual Presting (1965) apresenta como possuindo pólen com quatro aberturas, e para $P$. edulis, na qual o mesmo autor apresenta grãos de pólen com oito a dez aberturas. Estas variações não foram observadas no material analisado neste trabalho. Ainda, $P$. tenuifila apresenta um intervalo maior de aberturas (6-10) do que o apresentado por Presting (1965) (6-8 aberturas).

Quanto ao tipo de aberturas, há divergências na literatura. Este estudo concorda com Spirlet (1965), Huynh (1972), Amela García et al. (2002) e Araújo \& Santos (2004), quanto à presença de colpos nestas espécies. Presting (1965) apresenta $P$. amethystina, $P$. caerulea e $P$. edulis com aberturas colporoidadas. Barrios et al. (2005) caracterizam o subgênero Passiflora (em 76 espécies analisadas) com aberturas colporoidadas. Discordamos destes autores neste estudo, no que se refere às aberturas, pois colporóides não foram observados para as espécies deste subgênero.

As espécies do subgênero Passiflora, assim como $P$. haematostigma, possuem pontopérculos (sensu Erdtman 1952 e Punt et al. 2007) ou opérculos primários (sensu Presting 1965). Nas espécies que apresentam, de forma constante, três aberturas $(P$. alata, $P$. amethystina, $P$. caerulea e $P$. edulis) este termo é apropriado para as descrições e não gera confusões. Entretanto, para as demais espécies ( $P$. actinia, $P$. elegans e $P$. tenuifila), nos quais é difícil o reconhecimento exato dos pontopérculos, propomos a utilização do termo mesocolpo para toda a região entre os pseudopérculos (Figs. 13-15). 
Tabela 1. Súmula dos tipos de aberturas dos grãos de pólen de espécies de Passiflora L., segundo diversos autores, comparados aos resultados obtidos neste trabalho (última coluna). Número de aberturas - tipo da abertura - (número de endoaberturas).

\begin{tabular}{|c|c|c|c|c|c|c|c|}
\hline Espécies estudadas & $\begin{array}{c}\text { Presting } \\
\text { (1965) }\end{array}$ & $\begin{array}{l}\text { Spirlet } \\
(1965)\end{array}$ & $\begin{array}{l}\text { Huynh } \\
(1972)\end{array}$ & $\begin{array}{l}\text { Amela Garcia } \\
\text { et al. (2002) }\end{array}$ & $\begin{array}{c}\text { Araújo \& Santos } \\
\text { (2004) }\end{array}$ & $\begin{array}{c}\text { Milward-de-Azevedo } \\
\text { et al. (2004) }\end{array}$ & $\begin{array}{c}\text { Este } \\
\text { estudo }\end{array}$ \\
\hline \multicolumn{8}{|l|}{ Subgênero Astrophea } \\
\hline $\begin{array}{l}\text { P. haematostigma Mart. } \\
\text { ex Mast. }\end{array}$ & - & - & - & - & - & - & 6 - cólporo (3) \\
\hline \multicolumn{8}{|l|}{ Subgênero Passiflora } \\
\hline P. actinia Hook. & 12 - colpo & - & - & - & - & - & 10-12 - colpo \\
\hline P. alata Curtis & 6 (4)- colpo & - & - & - & 6 - colpo & - & 6 - colpo \\
\hline P. amethystina Mik. & 6 - colporóide (6) & 6 - colpo & - & - & - & - & 6 - colpo \\
\hline P. caerulea $\mathrm{L}$. & 6 - colporóide (6) & 6 - colpo & 6 - colpo & 6 - colpo & - & - & 6 - colpo \\
\hline P. edulis Sims & $\begin{array}{c}6(8-10)- \\
\text { colporóide }(6-10)\end{array}$ & 6 - colpo & - & - & - & - & 6 - colpo \\
\hline P. elegans Mast. & - & - & - & - & - & - & 8-10 - colpo \\
\hline P. tenuifila Kill. & 6-8 - colpo & - & - & - & - & - & 8-10 (6) - colpo \\
\hline \multicolumn{8}{|l|}{ Subgênero Decaloba } \\
\hline P. capsularis L. & 12 - cólporo (12) & - & $\begin{array}{c}12- \\
\text { cólporo }\end{array}$ & - & - & 12 - cólporo & 12 - cólporo (12) \\
\hline P. misera H.B.K. & 6 - cólporo* $(6)$ & - & - & 12 - colpo & 6 - colpo* & 12 - cólporo & 6 - cólporo* (6) \\
\hline P. morifolia Mast. & 6 - cólporo* (6) & - & - & - & - & 12 - cólporo & 6 - cólporo* (6) \\
\hline P. suberosa $\mathrm{L}$. & 6 - cólporo* (6) & - & $\begin{array}{c}6- \\
\text { cólporo* }\end{array}$ & 12 - colpo & 6 - colpo* & 12 - colpo & 6 - cólporo* $(6)$ \\
\hline P. truncata Regel & - & - & - & - & - & 6 - cólporo & 6 - cólporo* $(6)$ \\
\hline
\end{tabular}

* com opérculos sobre as aberturas.

As espécies do último subgênero estudado, Decaloba (Figs. 16-34), possuem uma característica peculiar que as une como grupo, mas que se apresenta derivada em algumas espécies e não muito fácil de ser visualizada: a presença de opérculos. P. misera (Figs. 17-18), P. morifolia, P. suberosa (Figs. 19-21) e P. truncata (Figs. 24-26) apresentam grãos de pólen 6-colporados, com opérculos sobre as aberturas (Figs. 16-26). P. suberosa eventualmente apresenta os colpos fusionados aos pares na região do apocolpo (Fig. 20). P. capsularis apresenta grãos 12-colporados (Figs. 27-34), com estreitas faixas de exina sobre algumas aberturas (Figs. 30-31). P. suberosa apresenta grandes endoaberturas sob os opérculos (Fig. 22a), de difícil visualização em microscopia óptica, mas evidentes na análise em MEV de material acetolisado, quando os opérculos caem (Fig. 23). P. misera e $P$. morifolia apresentam endoaberturas relativamente menores e opérculos largos (Fig. 22b), ao passo que em P. truncata estas endoaberturas são pequenas e os opérculos, sobre elas, são estreitos (Figs. 22c, 24-26).

Presting (1965) afirma, em sua teoria sobre a evolução das aberturas dos grãos de pólen de Passifloraceae, que os grãos de pólen descritos acima e característicos de espécies atualmente pertencentes à Decaloba, têm origem a partir de grãos 6-colporados (novamente como os de P. haematostigma), mas que sobre as aberturas houve a formação de estreitas faixas de ectexina, que, progressivamente, tornaram-se mais largas até a caracterização de um opérculo, que o autor denomina de opérculo secundário (die
Sekundäropercula), diferenciando-o do opérculo primário (formado anteriormente e ainda presente nestes grãos de pólen). O opérculo secundário, tal como se apresenta nestas espécies, corresponde ao próprio conceito de opérculo (opercullum) de Wodehouse (1935), adotado por Punt et al. (2007). Assim, este termo é aconselhado em lugar de opérculo secundário para a caracterização destes tipos de aberturas. Devido à dificuldade de diferenciar, nestes grãos de pólen, as áreas de pontopérculos ou opérculo primário (3) das de mesocolpo (3), com larguras bastante próximas, empregou-se para estas regiões unicamente o termo mesocolpo (Figs. 17, 21 e 24). Outra característica que comprova que esta parte da esporoderme é um opérculo é a estruturação diferenciada da exina nesta região. Passiflora misera e $P$. suberosa apresentam diferenças entre a nexina presente nos opérculos e mesocolpos. Em P. misera, na região do opérculo (local da endoabertura), a nexina 2 é menos espessa que aquela encontrada nos mesocolpos (Fig. 18). Já em $P$. suberosa (Fig. 19), observa-se uma densidade diferenciada na coloração da nexina 1 (corada com Azul de Toluidina), entre opérculo e mesocolpo (mais denso), sugerindo uma constituição química e/ou estrutural diferenciada.

A partir dos grãos 6-colporados, operculados, podem surgir novas formas, mais complexas, e cuja interpretação das partes resultantes torna ainda mais importante o conhecimento sobre a origem e evolução das aberturas nessa família. Esta nova forma é representada neste estudo por $P$. capsularis. Nesta espécie, além da presença dos opérculos, 


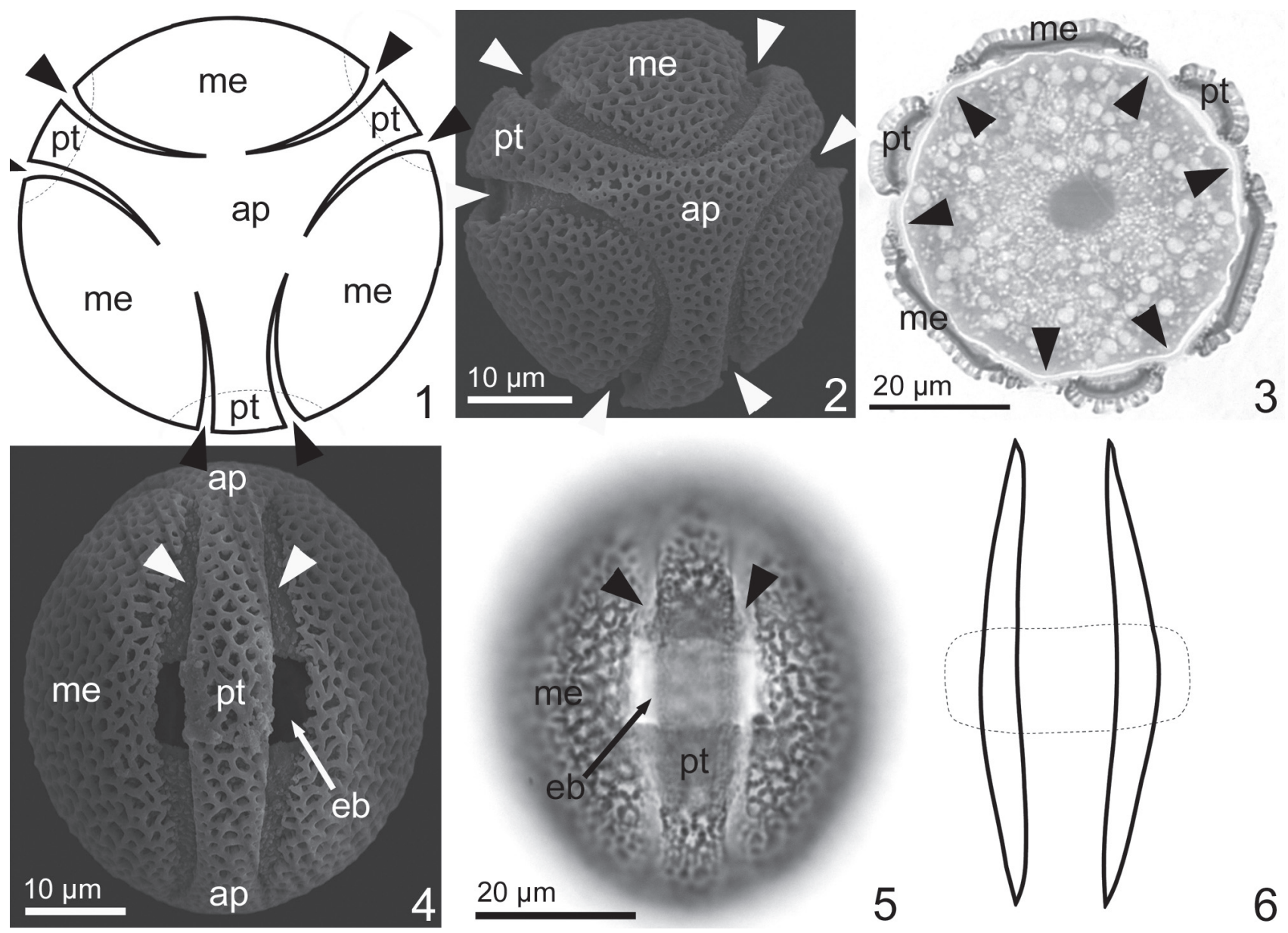

Figuras 1-6. Estrutura das aberturas dos grãos de pólen de Passiflora L. - subgênero Astrophea (P. haematostigma). 1. Esquema do grão de pólen em vista polar. 2. Grão de pólen acetolisado, em vista polar, sob microscopia eletrônica de varredura (MEV). 3. Seção semifina do grão de pólen, no nível da região equatorial (microscopia óptica de campo claro). 4. Grão de pólen acetolisado, em vista equatorial (MEV). 5. Grão de pólen acetolisado, em vista equatorial (microscopia óptica de campo claro), destacando a endoabertura. 6. Esquema de um par de aberturas e a endoabertura. Abreviaturas: ap, apocolpo; eb, endoabertura; me, mesocolpo; pt, pontopérculo. Pontas de setas, aberturas. Linhas pontilhadas, delimitação das endoaberturas.

as extremidades de cada abertura se unem, aos pares, com as extremidades da abertura vizinha, tal como acontece nas espécies do subgênero Passiflora analisadas neste estudo, delimitando um pseudopérculo. Assim, têm-se como estruturas resultantes três pontopérculos, seis opérculos e três pseudopérculos (Figs. 27 e 28). No entanto, embora Presting (1965) tenha denominado as regiões de pseudopérculo em $P$. capsularis, o mesmo não se enquadra totalmente no conceito do autor, pois representa somente a união das ectoaberturas, enquanto que a endexina mantém estas regiões fortemente unidas e, funcionalmente, não é um opérculo, como facilmente visualizado nas preparações palinológicas, onde não há o desprendimento desta região.

Da mesma forma, os opérculos de $P$. capsularis não se desprendem após a acetólise, indicando que algo mantém estas estruturas presas no restante da esporoderme. A razão se revela quando visualizada a superfície interna do grão de pólen, próxima das endoaberturas (Fig. 32). Nesta região, são depositadas faixas de endexina (nexina 2) que, como resultado, individualizam duas endoaberturas (Fig. 34), uma de cada lado do opérculo e prendem o opérculo ao restante da sexina. Assim, no grão de pólen de P. capsularis, há 12 endoaberturas e o opérculo não é uma estrutura funcional, separando duas ectoaberturas (e consequentemente há 12 ectoaberturas), local onde o tubo polínico irá germinar. Em grãos de pólen acetolisados (Fig. 33), esta individualização não pode ser facilmente observada em microscopia óptica de campo claro, destacando a importância do uso de outros métodos de análise, como a microscopia eletrônica de varredura. Uma seção semifina do grão de pólen mostra claramente, para esta espécie, a existência de 12 regiões onde a intina é mais espessa e saliente (Fig. 29), demarcando as aberturas, contraponto com somente seis regiões observadas em $P$. suberosa (Fig. 19). Além disso, as regiões correspondentes aos opérculos em $P$. capsularis não possuem a estrutura da esporoderme diferenciada das demais regiões (Fig. 29).

Com relação ao número e tipo de abertura, há consenso entre as descrições polínicas para $P$. capsularis (Presting 1965; Huynh 1972; Milward-de-Azevedo et al. 2004). O mesmo não ocorre com as demais espécies. Passiflora mi- 
sera, P. morifolia e $P$. suberosa são descritas por Presting (1965) e P. suberosa por Huynh (1972) como possuindo grãos de pólen 6-colporados, com opérculos, concordando com os resultados apresentados para as espécies analisadas neste estudo. Araújo \& Santos (2004) descrevem o pólen de P. misera e P. suberosa, em microscopia óptica de campo claro, como 6-colpados. A presença de endoaberturas foi confirmada, neste estudo, para estas espécies, embora
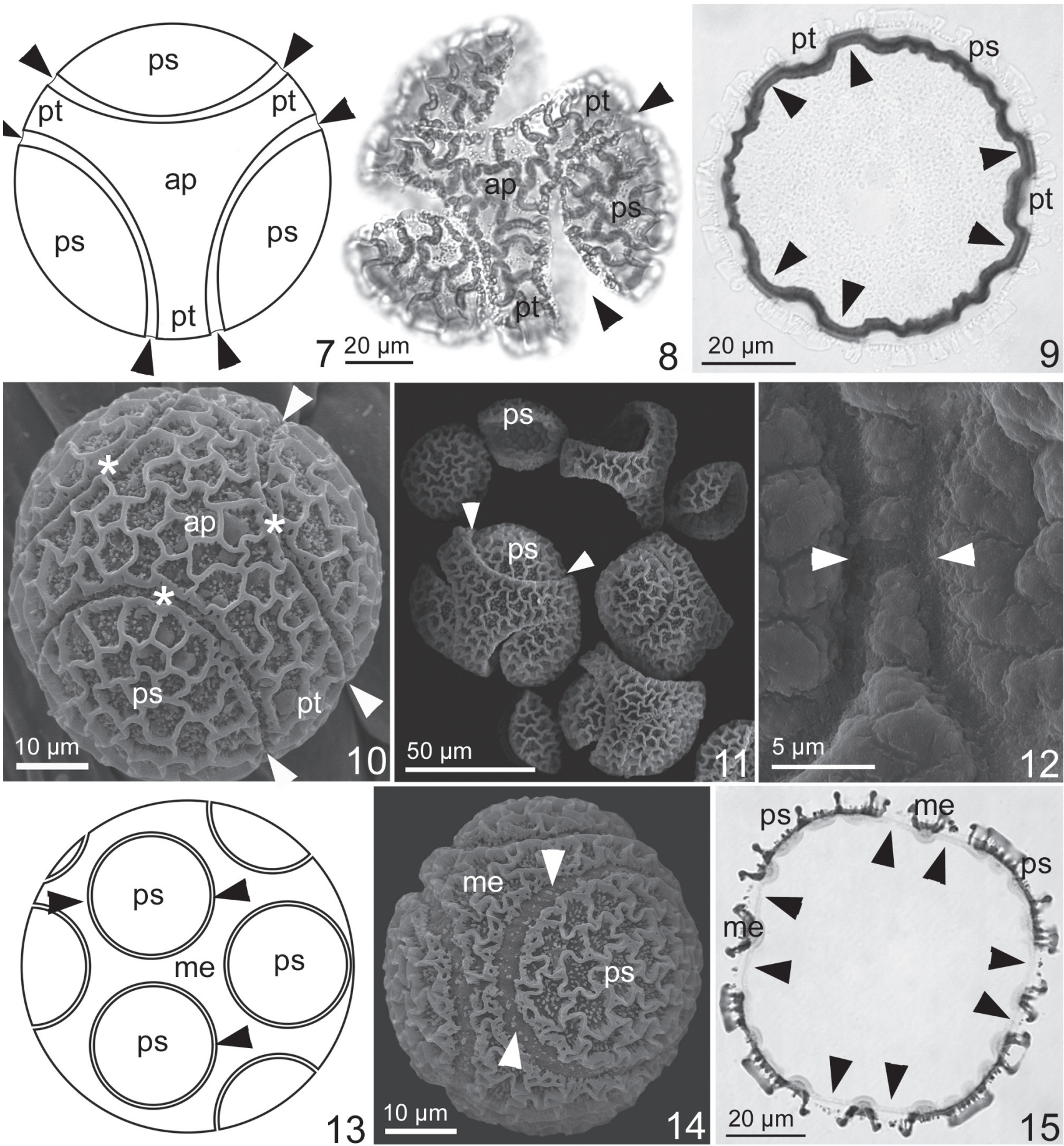

Figuras 7-15. Estrutura das aberturas dos grãos de pólen de Passiflora L. - subgênero Passiflora. 7. Esquema de um grão de pólen 6-colpado, em vista polar. 8. Grão de pólen acetolisado de $P$. alata, em vista polar (microscopia óptica de campo claro). 9. Seção semifina do grão de pólen, no nível da zona equatorial, de $P$. amethystina, 6-colpado, com coloração da intina (microscopia óptica de campo claro). 10. Grão de pólen de $P$. caerulea, em vista equatorial inclinada (microscopia eletrônica de varredura (MEV)). 11. Grãos de pólen acetolisados de P. amethystina, mostrando o desprendimento dos pseudopérculos (MEV). 12. Detalhe da superfície interna das aberturas do grão de pólen acetolisado e fraturado de P. tenuifila, mostrando a ausência de endoaberturas (MEV). 13. Esquema de um grão de pólen com mais de 6 colpos. 14. Grão de pólen de P. tenuifila, 8-colpado (MEV). 15. Seção do grão de pólen acetolisado de P. actinia, mostrando 8 aberturas (microscopia óptica de campo claro). Abreviaturas: ap, apocolpo; me, mesocolpo; ps, pseudopérculo; pt, pontopérculo. Pontas de setas, aberturas; *, fusão das aberturas no apocolpo. 

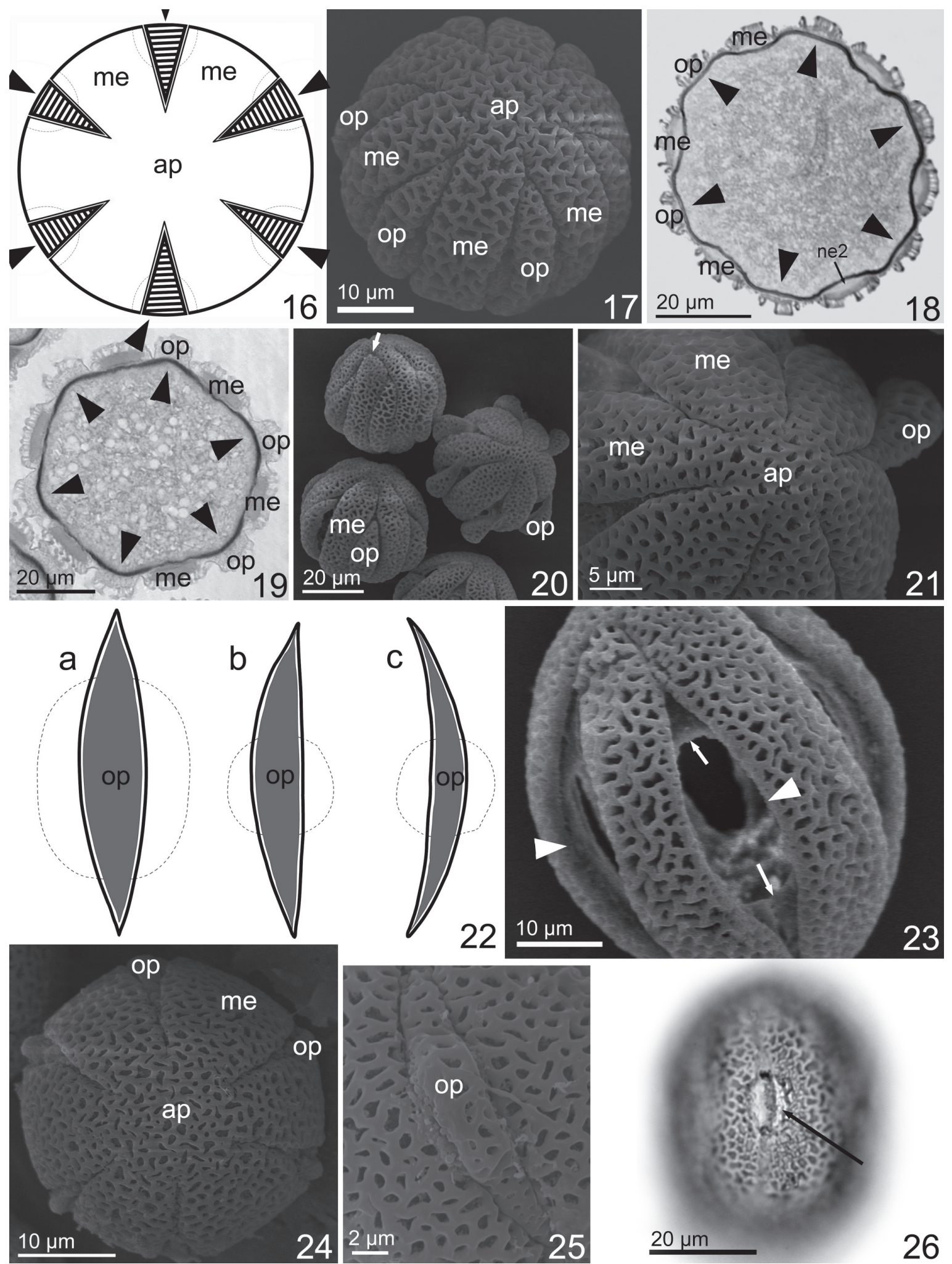

Figuras 16-26. Estrutura das aberturas dos grãos de pólen de Passiflora L. - subgênero Decaloba. 16. Esquema de um grão de pólen 6-colporado operculado, em vista polar (opérculos hachurados). 17. Grão de pólen de P. misera em vista polar inclinada (microscopia eletrônica de varredura - MEV). 18-19. Seção semifina do grão de pólen, no nível da zona equatorial, de $P$. misera (18) e P. suberosa (19), mostrando a posição dos opérculos e aberturas (microscopia óptica de campo claro). 20. Grãos de pólen acetolisados de $P$. suberosa, mostrando opérculos parcialmente desprendidos e fusão parcial no apocolpo (seta) (MEV). 21. Grãos de pólen acetolisados de $P$. suberosa, mostrando o apocolpo em detalhe (MEV). 22. Esquema das endoaberturas do grão de pólen de P. suberosa (a), P. misera e P. morifolia (b) e $P$. truncata (c). 23. Grão de pólen de P. suberosa sem os opérculos, mostrando a endoabertura (setas) (MEV). 24. Grão de pólen de P. truncata, em vista polar (MEV). 25. Detalhe do opérculo do grão de pólen de $P$. truncata (MEV). 26. Grão de pólen acetolisado de $P$. truncata, mostrando endoabertura (seta) (microscopia óptica de campo claro). Abreviaturas: ap, apocolpo; me, mesocolpo; ne2, nexina 2; op, opérculo. Pontas de setas, aberturas. Linhas pontilhadas, delimitação das endoaberturas. 


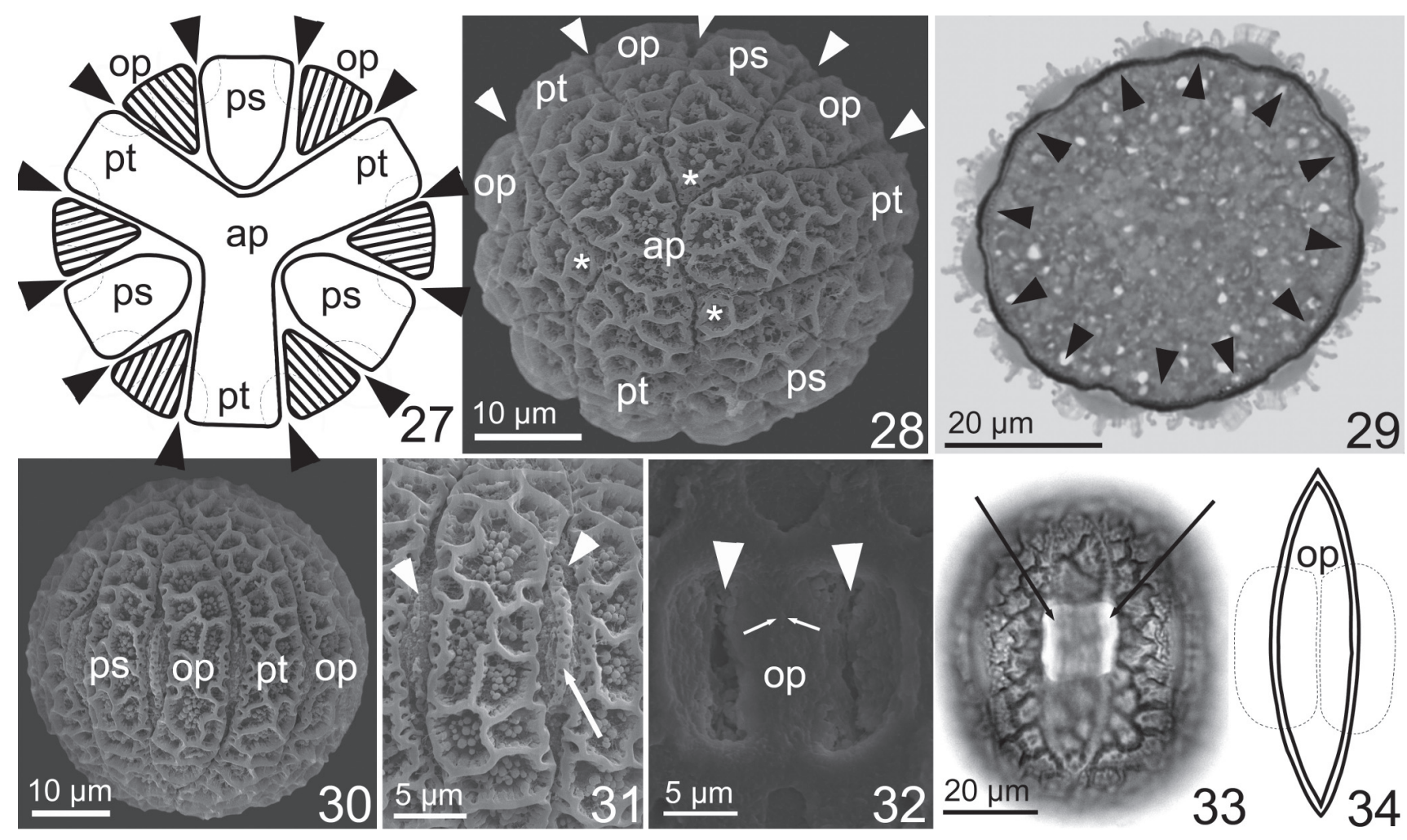

Figuras 27-34. Estrutura das aberturas dos grãos de pólen de Passiflora L. - subgênero Decaloba (P. capsularis). 27. Esquema de um grão de pólen 12-colporado, em vista polar (opérculos hachurados). 28. Grão de pólen, em vista polar (microscopia eletrônica de varredura - MEV). 29. Seção semifina do grão de pólen, com 12 indicadas (setas), no nível da zona equatorial (microscopia óptica de campo claro). 30. Grão de pólen em vista equatorial (MEV). 31 . Detalhe do mesocolpo, mostrando uma estreita faixa de exina sobre uma das aberturas (seta) (MEV). 32. Detalhe da superfície interna, mostrando duas endoaberturas, separadas por uma estreita deposição de nexina 2 (entre as setas finas), em grão de pólen acetolisado e fraturado (MEV). 33. Grão de pólen acetolisado, mostrando a localização das endoaberturas (setas) (microscopia óptica de campo claro). 34. Esquema da ectoabertura e endoaberturas, com base na interpretação das Fig. 32-33. Abreviaturas: ap, apocolpo; op, opérculo; ps, pseudopérculo; pt, pontopérculo. Pontas de setas, aberturas. *, fusão das aberturas no apocolpo. Linhas pontilhadas, delimitação das endoaberturas.

sejam de difícil visualização em $P$. suberosa. Em P. misera, são bastante evidentes em técnicas simples de microscopia óptica. Barrios et al. (2005) descrevem os grãos de pólen do subgênero Decaloba como 6 ou 12-colporados, não discriminando as espécies.

Amela García et al. (2002) descrevem o grão de pólen de P. misera e P. suberosa como 12-colpados e Milward-deAzevedo et al. (2004) referem-se a grãos de pólen 12-colporados para $P$. misera e $P$. morifolia, 12-colpados para $P$. suberosa e 6-colporados, sem opérculos, para $P$. truncata. Quanto à presença de endoabertura, possivelmente as técnicas utilizadas pelos autores não permitiram a visualização destas estruturas nos pólens descritos como colpados. $P$. truncata apresentou, neste estudo, a presença de opérculos, ainda que estreitos, ao contrário do descrito por Milwardde-Azevedo et al. (2004).

Com relação ao número de aberturas, a discordância é ainda maior e gerada por um grave equívoco na interpretação da teoria de Presting (1965), além de um conflito com a própria definição de abertura utilizado por Punt et al. (2007). Amela García et al. (2002) e Milward-de-Azevedo et al. (2004) interpretam cada uma das laterais dos opérculos como uma abertura, que estariam fusionadas nas extremidades, de modo que estes grãos de pólen possuiriam 12 aberturas. Milward-de-Azevedo et al. (2004), inclusive, utiliza o termo pseudopérculo para a região entre as aberturas (correspondente ao opérculo). Como ressaltado, neste estudo e por Presting (1965), a presença de 12 aberturas nos grãos de pólen de Passiflora somente ocorre quando há deposição de endexina na superfície interna do opérculo. Assim, esta estrutura se fusiona ao restante da exina e não mais se desprenda durante o crescimento do tubo polínico. Entre as 106 espécies de Passiflora analisadas por Presting (1965) (aproximadamente 20\% das espécies do gênero), somente quatro são caracterizadas como 12-colporadas: $P$. capsularis, P. hahnii (E. Fourn.) Mast., P. pohlii Mast. e a maioria dos grãos de pólen de $P$. biflora Lam., indicando que a presença de 12 aberturas é uma característica rara para o gênero.

Considerando-se a análise da teoria de Presting (1965) e Spirlet (1965) sobre a origem das aberturas, os quais afirmam que a fusão das ectoaberturas ocorre somente entre as extremidades da abertura de um par com a extremidade de uma abertura do par vizinho, a utilização do termo pseudopérculo por Amela García et al. (2002) e Milward-de-Azevedo et 
al. (2004) parece ser equivocada, já que as "aberturas" de um mesmo par, interpretadas por esses autores, estariam fusionadas entre si.

Esta variação de opiniões, entre 6 e 12 aberturas nos grãos de pólen dessas espécies, certamente não está relacionada com algum tipo de variabilidade intraespecífica, especialmente em relação à $P$. suberosa, visto todas as condições para a formação de um grão de pólen com 12 aberturas. Além disso, a análise das ilustrações apresentadas pelos autores (Amela García et al. 2002; Araújo \& Santos 2004; Milward-de-Azevedo et al. 2004) mostra tratar-se de grãos de pólen morfologicamente bastante semelhantes, variando somente a interpretação dos autores.

Este estudo torna evidente a importância da utilização de várias técnicas de microscopia para a análise dos tipos de aberturas, especialmente nesse gênero tão diverso do ponto de vista palinológico, como Passiflora. A uniformização dos termos por parte dos autores torna-se essencial para que os dados gerados nos estudos palinológicos possam ser utilizados em estudos taxonômicos e filogenéticos. A interpretação equivocada de estruturas, como o número e tipos de aberturas, podem comprometer a confecção de chaves polínicas, como a apresentada por Milward-de-Azevedo et al. (2004), onde estas características são utilizadas para a entrada na chave.

Conforme a nova classificação infragenérica de Passiflora (Feuilett \& MacDougal 2003), este estudo apóia a existência de duas linhas principais de desenvolvimento das aberturas em Passiflora, correspondente aos subgêneros Passiflora, com tendência à fusão dos colpos aos pares, delimitando pseudopérculos circulares e distribuídos uniformemente ao longo do grão, e o subgênero Decaloba, com o desenvolvimento de opérculos sobre os cólporos e também com tendências de fusões de aberturas em poucas espécies. O subgênero Astrophea possui aberturas mais próximas, morfologicamente, às descritas para o subgênero Passiflora, indicando a proximidade filogenética destes dois subgêneros, como já apontado por Muschner (2005) e Hansen et al. (2006).

\section{Agradecimentos}

Os autores agradecem a Renan Theodor Dettke, pela confecção dos desenhos esquemáticos dos grãos de pólen, e à bióloga Érica Duarte, pela revisão do abstract. Agradecemos, também, à Profa. Dra. Maria Luisa Lorscheitter, pela leitura crítica do manuscrito e sugestões. Agradecemos, finalmente, aos responsáveis pelo Laboratório de Anatomia Vegetal (LAVeg) do Departamento de Botânica, Instituto de Biociências, UFRGS e Centro de Microscopia Eletrônica (CME) da UFRGS, onde o trabalho foi executado.

\section{Referências bibliográficas}

Amela García, M.T.; Galati, B.G. \& Anton, A.M. 2002. Microsporogenesis, microgametogenesis and pollen morphology of Passiflora spp. (Passifloraceae). Botanical Journal of the Linnean Society 139: 383-394.
Araújo, R.C.M. \& Santos, F.A.R. 2004. Palinologia de espécies do gênero Passiflora L. (Passifloraceae) da Chapada Diamantina, Bahia, Brasil. Sitientibus, série Ciências Biológicas 4(1/2): 37-42.

Barrios, L.; Caetano, C.M.; Cardoso, C.I.; D'Eeckenbrugge, G.C.; Arroyave, J.A. \& Olaya, C.A. 2005. Caracterización del pollen de especies de los géneros Passiflora e Dilkea. Acta Agronômica 54(3): 19-23.

Cervi, A.C. 2006. O gênero Passiflora L. (Passifloraceae) no Brasil, espécies descritas após o ano de 1950. Adumbrationes ad Summae Editionem 16: 1-5.

Claugher, D. 1986. Pollen wall structure, a new interpretation. Scanning Electron Microscopy 1: 291-299.

Erdtman, G. 1952. Pollen morphology and plant taxonomy Angiosperms. Waltham, Chronica Botanica Co.

Erdtman, G. 1960. The acetolysis method. A revised description. Svensk Botanisk Tidskrift 39: 561-564.

Escobar, L.K. 1989. A new subgenus and five new species in Passiflora (Passifloraceae) from South America. Annals of the Missouri Botanical Garden 76: 877-885.

Faegri, K. \& Iversen, J. 1964. Textbook of pollen analysis. Oxford, Blackwell Scientific Publications.

Feuillet, C. \& Macdougal, J.M. 2003. A new infrageneric classification of Passiflora L. (Passifloraceae). Passiflora 13: 34-38.

Feuillet, C. \& Macdougal, J.M. 2007. Passifloraceae. Pp. 270-281. K. Kubitzki (Ed.) The families and genera of vascular plants. Vol. 9. Berlin, Springer.

Fischer, H. J. 1890. Beiträge zur vergleichenden Morphologie der Pollenkörner. Breslau. Fritzsche, J. 1837. Über den Pollen. Mémoires des Savants Étrangers. Vol.3. Petersburg.

Gerrits, P.O. \& Smid, L. 1983. A new, less polymerization system for the embedding of soft tissues in glicol methacrylate and subsequent preparing of serial sections. Journal of Microscopy 132: 81-85.

Hansen, A.K.; Gilbert, L.E.; Simpson, B.B.; Downie, S.R.; Cervi, A.C. \& Jansen, R.K. 2006. Phylogenetic relationships and chromosome number evolution in Passiflora. Systematic Botany 31(1): 138-150

Huynh, K.L. 1972. Étude de l'arrangment du pollen dans la tétrade chez les Angiopermes sur la base de dones cytologiques - IV Le genre Passiflora. Pollen et Spores 14: 51-60.

Jensen, W.A. 1962. Botanical histochemistry - principles and practice. San Francisco, W.H.Freeman and Company.

Killip, E. 1938. The American species of Passifloraceae. Field Museum of Natural History, Botanical Series 19: 1-613.

Milward-De-Azevedo, M.A.; Gonçalves-Esteves, V. \& Baumgratz, J.F. 2004. Palinotaxonomia das espécies de Passiflora L. subg. Decaloba (DC.) Rchb. (Passifloraceae) no sudeste do Brasil. Revista Brasileira de Botânica 27(4): 655-665.

Mohl, H. 1834. Beiträge zur Anatomie und Physiologie der Gewächse: Über den Bau und die Formen der Pollenkörner. Bern, Chr. Fischer und Comp.

Muschner, V.C. 2005. Filogenia molecular, taxas evolutivas, tempo de divergência e herança organelar em Passiflora L. (Passifloraceae). Tese de Doutorado, Universidade Federal do Rio Grande do Sul, Porto Alegre.

Muschner, V.C.; Lorenz, A.P.; Cervi, A.C.; Bonatto, S.L.; Souza-Chies, T.T.; Salzano, F.M. \& Freitas, L.B. 2003. A first molecular phylogenetic analysis of Passiflora (Passifloraceae). American Journal of Botany 90(8): 1229-1238.

O'Brien, T.P. \& McCully, M.E.. 1981. The study of plant structure principles and selected methods. Melbourne, Termarcarphi Pty.

Presting, D. 1965. Zur morphologie der Pollenkörner der Passifloraceen. Pollen et Spores 7: 193-247.

Punt, W., Hoen, P.P., Blackmore, S., Nilsson, S. \& Le Thomas, A. 2007. Glossary of pollen and spore terminology. Review of paleobotany and Palynology 143: 1-81.

Roland, J.C. \& Vian, B. 1991. General preparation and staining of thin sections. Pp.1-66. In: J.L HALL \& C. HAWES (Eds.) Electron Microscopy of Plant Cells. London, Academic Press.

Souza-Chies, T.T.; Yockteng, R. \& Nadot, S. 2005. Systématique moléculaire comparée en France et au Brésil du genre Passiflora L. (Passifloraceae). Cahiers Agricultures 14(2): 209-215. 
Spirlet, M.L. 1965. Utilisation taxonomique des grains de pollen de Passifloracées. Pollen et Spores 7: 249-301.

Thanikaimoni, G. 1986. Pollen apertures: form and function. Pp. 119-136. In: S. Blackmore \& I.K. Fergunson (Eds.) Pollen and Spores: form and function. London, Academic Press.
Wodehouse, R.P., 1935. Pollen Grains. Their structure, identification and significance in science and medicine. New York, McGraw-Hill. Yockteng, R. \& Nadot, S. 2004. Phylogenetic relationships among Passiflora species based on te glutamine synthetase nuclear gene expressed in chloroplast ( $n c p$ GS). Molecular Phylogenetics and Evolution 31: 379-396. 